\title{
Bakhtin, prefaciador de Ressurreição de Leon Tolstoi: marxista, dissimulante ou errante?
}

Fernando Antônio Dusi Rocha ${ }^{1}$

Dez anos já haviam passados desde a publicação de Ana Karenina (1877), quando Tolstoi (1976) começou a trabalhar em seu último romance, Ressurreição. Durante essa década lacunar, o Conde Tolstoi viveu uma profunda crise: crise de vida, de ideologia e de criatividade artística. Ele renunciou a todas as suas propriedades em favor de sua família, declarou que suas primeiras visões de mundo eram falsas e rejeitou seus trabalhos literários.

Em fins de 1899, restou publicada a obra, como volume treze da coleção do autor. Mikhail Bakhtin (1989) prefaciou esse volume: um prefácio absolutamente peculiar aos passos seguintes de sua atribulada carreira teórica. Um prefácio que estaria a denunciar um Bakhtin (1989) com forte tendências marxistas, por entender que a ruptura de vida de Leon Tolstoi não se limitava à sua vida pessoal. Com efeito, diz Bakhtin, no mencionado prefácio (1989, pág. 237, livre tradução): “[...] a ruptura era preparada para e estimulada por complexos processos socioeconômicos e ideológicos levados a cabo na vida social russa, processos que exigiam de um artista formado em outra época mudanças em sua inteira orientação criativa." 2

A reorientação social na ideologia e criatividade artística de Tolstoi teria sido uma resposta inevitável às mudanças das condições da época. Mas serve também para avaliar a orientação ideológica do próprio prefaciador de Ressurreição. Afinal, a pergunta que se faz é a seguinte: nesse longo prefácio, pode-se entrever num Bakhtin primevo fortes injunções marxistas, ou apenas uma relação de encobrimento, dissimulante ou errante?

Esse, afinal, o objeto do presente ensaio.

Ressurreição é baseada num fato real, muito embora Tolstoi sempre prescindisse de bases concretas em suas obras.

No verão de 1887 - contam Irene e Laura Andresco (1976), tradutoras do romance em versão espanhola- o célebre juiz Koni contou a Tolstoi que um jovem de família aristocrática, ao tomar parte de um júri, reconheceu na ré, a quem se acusava de assassinato, uma moça que havia seduzido em seus anos moços e que posteriormente teria caído na maior abjeção da sociedade. Sentindo-se culpado por aquilo, resolveu redimir seu pecado, casando-se com ela. Tinha começado a ajustar as coisas, mas, neste

1 Mestre em Literatura pela Universidade de Brasília e Doutorando em Literatura no departamento de Teoria literária e Literaturas pela mesma univerisidade.

2 No original: "[...] the rupture was prepared for and stimulated by complex socioeconomic and ideological processes being accomplished in Russin social life, processes demanding from an artist who had been formed in another epoch changes in his entire creative orientation". 
entretempo, a moça morreu de tifo no cárcere. Koni ignorava a sorte ulterior do jovem aristocrata.

O relato impressionou profundamente a Tolstoi, que pediu permissão ao magistrado para descrevê-lo em um periódico. Mas desistiu da ideia e começou a escrever o romance. A publicação somente ocorreu doze anos depois do fato, simultaneamente em francês, inglês e alemão. Mas na Rússia, as edições foram mutiladas para não se chocarem com a censura czarista. Com efeito, observam as tradutoras, em nota preliminar ao romance:

Desse modo, em fins de 1899, aos setenta anos, Tolstoi criou uma grande novela políticosocial, considerada com justiça como o cume do realismo crítico na criação do escritor. Na obra palpita a inerente ênfase acusadora de Tolstoi e se formula de modo cortante os "malditos problemas" contemporâneos que atormentavam o autor. ( ANDRESCO, Irene; ANDRESCO,Laura, 1976, pág. 1598). ${ }^{3}$

A estrutura de Ressurreição, afirma Bakhtin (1989) difere profundamente da estrutura de suas novelas anteriores. Segundo o teórico russo, podemos assinalar no último romance tolstoiano uma "categoria genérica especial". Guerra e Paz é um romance histórico familiar, com forte inclinação épica; Ana Karenina, um romance psicológico familiar; e Ressurreição deve ser assinalada como um sócio ideológico. Julgado em termos genéricos, o romance pertenceria ao mesmo grupo do romance de Chernyshevsky, $O$ que é para ser feito?, ou De quem é a culpa?, de Herzen, e, no Ocidente, os romances de George Sand. A crítica da realidade feita por Tolstoi é acompanhada - ou interpretada por - provas diretas da tese sobre um "desejado e obrigatório sistema social". Essas provas são apresentadas na forma de argumentos abstratos ou admoestações, ou algumas vezes por tentativas de representar um ideal utópico - continua Bakhtin.

$\mathrm{Na}$ busca das características fundamentais do gênero, o romance, segundo Bakhtin (1989) é composto por três aspectos: (i) uma crítica radical a todas as relações sociais existentes e disponíveis; (ii) um retrato da "causa espiritual" dos herois, ou seja, a ressurreição moral dos protagonistas, Nekhlyudov e Katyusha Maslova; e (iii) o desenvolvimento abstrato da visão sóciomoral e religiosa do autor.

Diferentemente dos romances anteriores, com suas várias e intrincadas relações pragmáticas e familiares, a narração é concentrada somente em torno de Nekhlyudov e em parte sobre Katyusha Maslova. Todas as demais personagens e todo o mundo remanescente são representados segundo o "campo de visão" de Nekhlyudov. Esse "campo de visão" ou "horizonte conceitual" tornar-se-á um importante conceito para Bakhtin no início dos anos 30, quando ele estende seus insights ao seu livro sobre Dostoiévsky na teoria do romance.

Não se pode perder de vista- adverte Bakhtin (1989) - que o Conde Tolstoi construiu sua carreira sobre bases arcaizantes, como defensor das tradições e princípios

\footnotetext{
${ }^{3}$ Texto original: “De este modo, hacia finales de 1899, a los setenta anos, Tolstoi creó una gran novela políticosocial, considerada con justicia como cumbre del realismo crítico del escritor. En la obra palpita El inherente ênfasis acusador de Tolstoi y se plantean de modo tajante los 'malditos problemas' contemporáneos que atormantaban al autor".
} 
dos novecentos, de Rousseau e de precoces sentimentalismos. Ele advogava a causa obsoleta do sistema da propriedade patriarcal, com base na escravidão e com irreconciliável inimizade com o desenvolvimento da burguesia liberal. No entanto, "a propriedade rural tolstoiana não é o lento mundo da vida real do senhor de escravos,um mundo adversamente isolado para uma vida emergente, cego e surdo para tudo na vida" - diz Bakhtin ${ }^{4}$. (1989, pág. 238, livre tradução). Bakhtin também não ignora a penetração de novas vozes nos anos 60, a mais tensa época ideológica da história russa. Essa "semiestilização" do estado feudal provocou em Tolstoi um criativo passo permitindo um passo inabalável em favor dos camponeses.

E por este motivo, as relações críticas do capitalismo emergente e tudo que se ajunta àquelas ideologias na psiquê humana, além do submisso pensamento ideológico, controlavam, desde o princípio, a base social no trabalho de Tolstoi, o mais distante possivel dos proprietários escravocratas. (BAKHTIN, 1976, pág. 238, tradução livre) ${ }^{5}$

Mas Bakhtin vai mais além em sua análise históricosocial. Nos anos 70 uma grande diferenciação já começava. O capitalismo estava se consolidando, com crueldade, relegando as forças sociais, desunindo vozes ideológicas, marcando profundas fronteiras. Esse processo se acentuou nos anos 80 e 90, quando as diferenças sociais na Rússia se aguçaram ainda mais: a crônica preservação da classe média proprietária, a burguesia liberal de todos os matizes, populistas e - o mais importante marxistas distinguindo-se dos demais grupos, executando sua própria ideologia, na qual a luta de classes tornava-se mais e mais evidenciada. Toda personalidade criativa deviase, a partir de então, orientar-se nessa luta social de forma ambígua "se for para manterse criativo".

Por óbvio, continua Bakhtin (1989), as formas artísticas ficaram sujeitas à mesma crise interna de diferenciação e realização de ocultas contradições. Tolstoi, o ideólogo, o moralista, o pregador estava apto a amoldar-se a uma nova "chave social", e ele torna-se, nas palavras de Lênin, o porta-voz de milhões de camponeses. Neste ponto do ensaio, Bakhtin cita o grande patriarca da Revolução:

Tolstoi é um notável instrumento para aquelas ideias e sentimentos que foram agregadas entre milhões de camponeses russos durante o começo da revolução burguesa na Rússia. Tolstoi é original, pela soma total de suas percepções, perigoso quando tomado como um todo, quando expressa as peculiaridades de nossa revolução como uma revolução burguesa campesina. As contradições das antevisões de Tolstoi nesse ponto de vista são um real espelho daquelas contradições dentro da qual a atividade histórica da classe camponesa foi inserida em nossa revolução. (LENIN,

\footnotetext{
${ }^{4}$ No texto de acesso: "The Tolstoian country estate is not the sluggish world of the real-life landlordserfowner, a world hostilely closed off from new emerging life, blind and deaf to everything iin that life". 5 "And for this reason, criticism of emerging capitalist relations and of everything that accompanies these relations in the human psyche and in obsequious ideological possessed, from the very beginninh, a social basis in Tolstoi's work far broader than the sef-owner's estate".
} 
Wladimir Ilitch, in Leo Tolstoy as the mirror of the Russian Revolution, apud BAKHTIN, 1989, pág. 240 - livre tradução). ${ }^{6}$

A crítica da realidade feita por Tolstoi - tal qual a do seu grande antecessor, Rousseau - é uma censura a "qualquer e toda convenção social, erigida pelo homem sobre a natureza", o que significa, por fim, que este exame da realidade parece negar qualquer autentica historicidade.

Exemplificando a crítica às convenções sociais feitas no romance em estudo, Bakhtin (1989) apresenta a cena do julgamento, como uma das mais poderosas páginas de Ressurreição. As citações do Evangelho escolhidas como epígrafe para a primeira parte do romance revelam a tese subliminar de Tosltoi: a absoluta impermissibilidade de qualquer pessoa ao julgar outra. Essa tese é justificada antes de tudo no enredo básico do romance: Nehklyudov, que se viu jurado no processo criminal de Maslova, ou seja, o julgador de Kathusha, é na verdade a pessoa culpada pelo seu opróbrio.

No plano de Tolstoi (1976), a cena do julgamento deveria ser emblemática, pois deveria demonstrar a total ilegitimidade dos verdadeiros julgadores: o presidente da corte, com seu bíceps, sua boa digestão e seu affair com a governanta; o espetáculo metrificado a ser encetado e seu mau humor por conta da mulher - que o influenciam durante o julgamento; a boa natureza do membro do Júri com seu catarro no estômago; e o promotor público com a obtusa ambição carreirista e sua falta de senso e tagarela pretensioso. Não há juízes legítimos ou dignos, pois a corte, em sua essência, é um mal e uma falsa invenção do homem.

Então, - percebe Bakhtin (1989) - sua rejeição ao Tribunal, na forma descrita, torna-se absoluta e por essa razão inescapável, não-dialética e contraditória. Sua visão artística e representação pictórica são amplas e invasivas à suposta estabilidade czarina. Ao rejeitar a classe burocrática da corte, Tolstoy afirma: o que vale é social, o soberano e não o formal, a corte legítima é a que julga a sociedade por si mesma e os juízes em nome da sociedade.

Tolstoi alcança a total rejeição de toda convenção social, de qualquer espécie. Mas sua tese ideológica, segundo Bakhtin, carece de qualquer senso de dialética histórica. De fato, suas cenas artísticas desmascaram apenas a convenção podre, que perdeu sua produtividade social e é preservada pelo regime no interesse da classe opressora. O niilismo tolstoiano, aplicando sua negação a toda cultura humana como algo convencionado e inventado pelo homem, é resultado da mesma má interpretação da dialética histórica - uma dialética que se esconde no interior da morte somente porque a vida tem que ocupar o seu lugar. Segundo Bakhtin, "Tolstoi somente vê a morte e o campo da história - assim vista por ele - permanece vazio".

\footnotetext{
6 "Tolstoy is great as spokeman of those ideas and sentiments that coalesced among millions of Russian peasants during the onset of the bourgeois revolution in Russia. Tolstoy is harmful when taken as a whole, expresses the peculiarities of our revolution as a peasant bourgeois revolution. The contradiction in Tolstoy's views, from this point of view, are a real mirror of those contradictory conditions into which the historical activity of peasantry has been placed in our revolution."
} 
Afinal - assegura Caryl Emerson (1989) -, Tolstoi é o poeta da morte, não por um amor à morbidade, mas como resultado natural do seu mundo fictício no qual os sistemas ideológicos existem para servir personalidades e não ao meio circulante.

Para Tolstoi, uma pessoa pode agir somente sobre si, sobre seu interior (o Reino de Deus que está dentro de nós). Todo o resto é meramente anexado. Aplicado esse pensamento às últimas páginas do romance, fica claro para Nekhlyudov que o mal somente pode ser vencido pela inatividade, pela não resistência a ele. Por essa razão, a ideologia devia inevitavelmente ligar-se ao plano subjetivo da realidade interna. Ideologia - consigna Bakhtin (1989) - indica um trajeto subjetivo, não percorrido pelo explorador arrependido, ou seja, por aqueles que ainda não se sentem suficientemente arrependidos para a penitência.

Em suma, o prefácio bakhtiniano conclui que a ideologia de Ressurreição está direcionada para os exploradores. As questões suscitadas por Tolstoi são desprovidas de perspectiva histórica: os representantes de uma classe ou estamento renunciado - como no caso do protagonista - não têm um fundamento objetivo no mundo exterior, nem causa histórica ou propósito, e por esse motivo concentram-se somente em seu mundo interior.

Não posso deixar de registrar um dos parágrafos finais do prefácio, que no caso do ensaio toma papel bastante significativo:

Em tempos recentes, nossa literatura soviética tem trabalhado tenazmente sobre a criação de novas formas para a ideologia do romance sócioideológico, Esse talvez seja o mais urgente e importante gênero da cena literário de hoje. $O$ romance sócioideológico - no final das contas o romance socialmente tendencioso - é uma forma artística completamente legítima [...] (BAKHTIN, 1989, destaque não original, livre tradução). ${ }^{7}$

Mas Tolstoi nunca foi uma unanimidade na recém criada e conturbada União Soviética. Outros teóricos o enxergavam de forma diversa da de Lênin, em citação feita por Bakhtin. Em nota de rodapé, o próprio Bakhtin refere-se Georgy Plekhanov, teórico marxista revolucionário, crítico e sociólogo da arte. Em ensaio, esse crítico argumenta que Tolstoy, contra o materialismo dialético de Marx, era um "metafísico idealista". Com isso Plekhanov quer dizer que Tolstoi significava um tipo de pensador binário cuja mente trabalhava melhor em oposições fechadas e "consistência absoluta". Além disso, ele criticava a doutrina tolstoiana da não violência como resistência ao mal e contra o banimento do capital, uma vez que insistia que julgamentos absolutos sobre o bem e o mal não poderiam ser feitos no mundo real (e relativo). (BAKHTIN, 1989, nota 8, pág. 301).

\footnotetext{
7 "In recent times our Soviet literature has been tenaciously laboring over the creation of new forms for the socioideological novel. This is perhaps the most pressing and important genre on today's literary scene. The socioideological novel - ultimately the socially tendentious novel - is a completely legitimate artistic form [...]"
} 
Ann Shukman (1989), escrevendo sobre os prefácios feitos por Bakhtin, tanto no romance Ressurreição, como nas peças teatrais - aqui não estudadas por fugirem ao objeto -, relatam o pano de fundo social do período de luta de classes e como tais prefácios expressaram a própria posição ideológica de Bakhtin naqueles momentos. Afirma ela (1989, pág. 137): "De todos os escritos assinados por Bakhtin, esses prefácios são os aparentemente mais marxistas em concepção e vocabulário". ${ }^{8}$

Diz Shukman que pode ser apressado julgar as afirmações do próprio Bakhtin (1989) feitas no prefácio de Ressurreição, no qual ele afirma que o romance é dirigido a exploradores e a representantes arrependidos da nobreza, naquele momento histórico em pleno declínio e expiração. Interessa à Shukman, sobretudo, a afirmação bakhtiniana de que essa incumbência de Tolstoi estava desprovida de qualquer perspectiva histórica. Segundo aquela teórica, além de apressado, é difícil de sustentar tão explícito e tão monológico escrito marxista, com referência à dialética histórica, ao "genuíno" entendimento de história, à luta de classes, aos explorados e exploradores.

É bem verdade que na edição de 1929 do livro de Dostoiévsky, Bakhtin destaca que uma análise imanente sociológica de estilo pode moldar a questão "das condições socioeconômicas para o nascimento do estilo". Mas a consideração de "refrações" das forças sociais num trabalho - continua Shukman (1989) - e as "imanentes avaliações sociais" com as quais ele é "diluído", são verdadeiramente um puxão de orelhas na declaração feita por Bakhtin, no prefácio a Tolstoi, no sentido de que "obviamente" todo trabalho de literatura é "completamente" determinado por [escritores] do período e pela disposição histórica as forças da classe social em um período.

É certo que os chamados livros contestados de Miedviédiev/Volochínov, publicados muito tempo depois do prefácio examinado, a verdade do argumento era estabelecer uma poética sociológica com a qual se pretendia reconhecer a natureza refratária de todas as construções ideológicas. Mas a questão dos livros contestados não é objeto deste ensaio. $\mathrm{O}$ que me interessa destacar é que, na primeira metade dos anos 20, em nenhum dos ensaios de Bakhtin que vieram a lume há qualquer consideração sobre história ou sociedade, muito menos sobre condições econômicas. São escritos filosóficos: um relato existencialista da responsabilidade (responsividade) humana, uma meditação quase filosófica sobre a natureza do homem e da criação literária e uma tentativa de fixar uma estética filosófica do texto literário. O Bakhtin dos finais dos anos 20 é, de modo geral, mais extrovertido: a linguagem, a literatura e o homem em si mesmo são agora concebidos como uma posição na interação do mundo real e social, "que choca e molda a consciência e a arte como consciência e a arte que refrata re responde a ela" - arremata Shukman (1989, págs. 140/141 - tradução livre).

Há, ainda, outra razão muito importante considerada por Shukman: um divisor de águas entre os prefácios de Tolstoi e tudo que Bakhtin (só ou no seu círculo) havia escrito até então. Nos prefácios as noções de mediação, refração e papel de linguagem e forma são postas de lado. Sua análise foca exclusivamente a ideologia de Tolstoi e de seus personagens.

\footnotetext{
8 "Of all Bakhtin's 'own name' writings the prefaces are the most apparently Marxist in conception and vocabulary"

9 "[...] which impinges on and shapes consciousness and arte as consciousness and art refracts and responds to it".
} 
Mas por seu tratamento do contexto histórico, os prefácios podem ser considerados como uma antecipação da poética histórica de Bakhtin os anos 30, dos excelentes escritos sobre história da novela e sobre Rabelais, que estariam por vir. (SHUKMAN, 1989, pág. 141, livre tradução). ${ }^{10}$

Ademais - prossegue a mesma autora - Bakhtin teria usado a tese de Tolstoi para "apresentar sua própria tese". Essa afirmação decorre do fato de que a faculdade de adoção tese de Tolstoi, feita por Bakhtin - uma escolha idiossincrática - e sua prolixa citação sobre o renascer de Nekhyudov surgem como uma súbita intrusão de "outra voz" dentro do teor sociológicomarxista, sustentado no prefácio como um todo. Mas, segundo Shukman, não se pode esquecer que os escritos assinados por Bakhtin também serviam de autorealização por meio da fé diante de necessidade de procurar a ajuda de Deus em confronto com o mal. Aliás, Clark \& Holquist (2004) cogitam que Bakhtin teria escrito os prefácios sobre Tolstoi diante da iminência de ser preso, já que sua atitude diante da fé cristã ortodoxa era totalmente hostil à política soviética. Os indícios dessa suspeita seguem do fato de que Bakhtin teria assinado alguns escritos em favor da religião.

Deixando de lado a questão religiosa, há ainda outros motivos apontados por Clark \& Holquist (2004) que põem em xeque o marxismo bakhtiniano. A expressa acusação, no intróito do prefácio em estudo, de que Tolstoi carece de "um senso dialético da história", bem como a declaração canônica de Lênin, de 1906, em Leon Tolstoi como Espelho da Revolução Russa, da qual derivaria a concepção partidária sobre o caráter patriarcal de Tolstoi, seriam sinal de que Bakhtin (1989) teria "aprendido a linguagem não só marxista como da crítica literária marxista soviética", com as suas últimas observações feitas no prefácio de Ressurreição.

A propósito da eleição do citado livro como modelo do romance sócioideológico, apropriado ao cânone da literatura soviética, refutam Clark \& Holquist (2004) que essa assertiva "pode conter um subtexto".

Mas este comentário de Bakhtin, louvando Ressurreição como sendo tal modelo, deve ser visto no contexto da falta de entusiasmo que demonstrou, em muitos outros escritos, no tocante a Tolstoi. A posição declarada pode ter constituído, pois, uma máscara a revestir uma de suas brincadeiras. Ele podia estar dando uma estocada no que viria a ser conhecido sob o nome de realismo socialista, ao identificá-lo com um romance da fase religiosa de Tolstoi. (CLARK \& HOLQUIST, 2004, pág. 180- destaque meu)

O que parece aos dois autores é que Bakhtin, nos dois ensaios feitos sobre Tolstoi, mostra grande tato, aquiescendo à concepção do establishment sobre o qual deveria acontecer à literatura soviética. Seu modo de trabalhar, inclusive com a citação de Lênin, era exatamente como o de outros estudiosos de mentalidade explicitamente partidária, inclusive Miedviédiev e Volochinov. Mas, ainda assim, insistem Clark \&

10 "But by their treatment of the historical context, the prefaces may be counted as a foretaste of Bakhtin's historical poetics of the 1930's, of the great writings on the history of the novel and on Rabelais that were to come". 
Holquist (2004): a conviç̧ão religiosa de Bakhtin não teria permitido que ele escrevesse textos de caráter não marxista, nem os prefácios, nem os textos disputados.

Sem requentar o debate, trago enfim o registro de Iná Camargo Costa (2005, pág. 277) sobre a questão. Segundo aquela professora, ao lado do marxismo introduzido por Plekhanov, pela construção do Partido Social Democrático Russo, "o marxismo legal teve grande e relevante presença na vida universitária e intelectual da Rússia no final do século XIX." Isso significa que, bem antes da Revolução de Outubro, o marxismo já constituía naquele país um "campo teórico inescapável a quem se candidatasse a qualquer papel relevante na vida política ou intelectual."

Não é preciso dizer nada do período imediatamente posterior à Revolução, uma vez que, contra ou a favor, os intelectuais se viram diante do imperativo de dialogar com a teoria que era a própria língua dos bolcheviques no poder ou, no mínimo, com suas variantes por assim dizer menos revolucionárias, como era o caso do marxismo legal. (COSTA, 2005, pág. 278)

Será mesmo que Bakhtin teria que sujeitar-se ao ideário marxista, de forma explícita no prefácio em comento? Ou até que ponto agiu de forma dissimulante ou mesmo errante para escapar de uma prisão iminente?

Bakhtin - segundo Morson \& Emerson (2008) - era hostil a todas as formas de teorismo. Isso foi uma constante em sua carreira. E, ao que tudo indica, mesmo após a Revolução de Outubro. Seus numerosos ataques à dialética, as críticas à concepção saussuriana da linguagem e as tentativas de esboçar uma teoria antagônica a Freud e Pavlov derivam todos da preocupação com a "eventividade do evento". Refletem também a crença numa sistematicidade da cultura, na não-finalizabilidade das pessoas e na centralidade da responsabilidade genuína para a experiência humana.

Mas o que me interessa relevar é que os mesmos autores dão destaque à "sabedoria prosaica" ou "inteligência prosaica", e amoldam o neologismo prosaística. Segundo eles, a prosaística, num primeiro sentido surge em oposição à poética. Num segundo sentido, é muito mais ampla do que a teoria da literatura: "é uma forma de pensar que pressupõe a importância do cotidiano, do comum, do "prosaico"”.

Ao desenvolver a prosaística no segundo sentido, Bakhtin segue outros pensadores, tanto russos como ocidentais, dos quais o mais significativo foi provavelmente o próprio Leon Tolstoi, autor do romance por ele prefaciado. Como Tolstoi, dizem Morson \& Emerson (2008, pág. 44), Bakhtin adverte reiteradamente que a rejeição aos absolutos não implica uma aceitação do relativismo ou do subjetivismo. Isso porque o relativismo e o subjetivismo estão localizados no reino da teoria abstrata e se encontram longe da "obrigatoriedade" e da "eventividade" do evento. Afirmam os mesmos autores: "Como fez tantas vezes ao longo da sua vida, Bakhtin insistia nesses primeiros escritos em que o relativismo (ou subjetivismo) e o absolutismo (ou 
dogmatismo) são duas faces da mesma moeda" (MORSON \& EMERSON, 2008, pág. 44)

De fato, Tolstoi (1976) era $\boldsymbol{o}$ ideólogo da prosaística, rejeitando claramente qualquer possibilidade de quaisquer leis da história ou qualquer ordem subjacente que pudesse explicar a desordem da vida diária. Da mesma forma, para Bakhtin (1989), "a ordem requer justificação, a desordem não. O estado natural das coisas é a bagunça" asseveram Morson \& Emerson (2008, pág.48).

Se a bagunça é estado desejado e desejável das coisas, o prefácio assinado por Bakhtin (1989) ao romance Ressurreição merece uma análise ainda mais progressiva do que as que foram feitas, do ponto de vista filosófico.

Em primeiro lugar, porque Tolstoi, na avaliação de Bakhtin (1989) deixa evidenciados alguns aspectos cruciais: (i) a absoluta impermissibilidade de qualquer pessoa julgar outra; (ii) o egoísmo como razão do arrependimento do nobre, ou seja sua exclusiva concentração no seu próprio "eu"; (iii) a forma de vencer o mal como sendo a a inatividade, a não resistência a ele.

O último aspecto acima descrito é que gera a controvérsia sobre a adoção ou não do ideário marxista na crítica feita a Tolstoi. Se, efetivamente, Bakhtin é seguidor da prosaística de Tolstoi, parece um contrasenso bakhtiniano afirmar que a ideologia não pode aliar-se ao plano subjetivo da realidade interna. A questão é complexa, mas não insolucionável.

Isso porque, numa tentativa inabitual de entender e interpretar Bakhtin, e mesmo o próprio Tolstoi, e sem adotar a tese de Clark \& Holquist, de que o prefácio é fruto de marotagem do autor, creio que esse imbróglio suscitado pelo filósofo russo no citado prefácio é proposital. Bakhtin quer demonstrar, por meio do velamento, do encobrimento, que nem o absolutismo nem o relativismo permeiam a obra de Toltoi. Não temo afirmar, com base numa aula de Heidegger, A essência da Verdade, publicado em Marcas do Caminho (2008), que Bakhtin pretendia demonstrar por meio do velamento a não-verdade do ente - aqui entendido como tudo aquilo de que falamos, aquilo a que, de um modo ou de outro, nos referimos, ou mesmo, o que e como nós mesmo somos. É bastante singular perceber que anos antes da aula do filósofo alemão (1930), Bakhtin, nos escritos primevos, pré e pós-revolução, pareciam dar provas de ser praticante de uma dissimulação proposital e provocativa, de encobrimento daquilo que na totalidade do ente é velado - isto é, o mistério. Aqui não se trata do mistério particular referente a isto ou àquilo, "mas do fato único de que o mistério (o encobrimento do que está velado) transpassa e impera como tal o ser-ai do homem.

Autorizo-me a citar Heidegger (2008): "A não-essência propriamente dita da verdade é o mistério". Bakhtin diria isso de outra forma: a dissimulação ou o encobrimento perfazem-se na não-finalizabilidade, como imanentes e essenciais à existência cotidiana. Só se fosse imanente e impessoal - dizem Morson \& Emerson - é que Bakhtin acreditava que a liberdade poderia ser real. Assim, o mistério não remanesceria na não essência ou na não verdade, mas na liberdade, que em Heidegger já tem o sentido de autonomia. Faço apenas a advertência que percorrer as marcas do caminho heideggerianas podem gerar o risco de avançar em metafísicos, no mínimo, inadequados à filosofia bakhtiniana. Por isso, contento-me com essas inflexões.

Assim entendo que o mascaramento surge como fórmula de comunicação possível nos prefácios de Tolstoi. Não só o velamento, como também a errância, pois 
tanto para este grande escritor quanto para Bakhtin, a desordem e a assistematicidade são o que determinam os rumos da humanidade. Heideggerianamente falando: a errância "é o cenário e o fundamento do erro". E o erro não é uma falta ocasional, mas o império (o domínio) da história, na qual se entrelaçam, confundidas, todas as modalidades do errar.

Em súmula curta: no prefácio em estudo prevalece um Bakhtin velado (simulado) e errante. Quanto ao fato de ter sido ou não marxista, o império da história já demonstrava a prevalência da errância - Bakhtin deu vários indícios disso ao longo de sua vida -, pouco importando as circunstâncias reinantes ou o cenário que o pressionassem ou não a escrever de forma a enaltecer a emergente literatura soviética.

Afinal, creio que sua não-finalizabilidade nunca foi deboche - muito menos idolatria da verdade.

\section{REFERÊNCIAS BIBLIOGRÁFICAS}

BAKHTIN, Mikhail. Preface to Vol. 13: Ressurretion. In: MORSON, Gary Saul; EMERSON, Caryl (Org.) Rethinking Bakhtin - Extensions and Challenges. Trad. Caryl Emerson. Evanston (IL): Northwerster University Press. 1989.págs. 237-257

COSTA, Iná Camargo. O marxismo Neokantiano do Primeiro Bakhtin. In: BRAIT, Beth (Org.) Bakhtin - dialogismo e construção do sentido. Campinas: Editora da Unicamp, 2005

CLARK, Katerina; HOLQUIST, Michael. Mikhail Bakhtin. Trad. J. Guinsburg. São Paulo: Perspectiva, 2004

EMERSON, Caryl. The Tolstoy Connection in Bakhtin. In: MORSON, Gary Saul; EMERSON, Caryl (Org.) Rethinking Bakhtin - Extensions and Challenges. Trad. Caryl Emerson. Evanston (IL): Northwerster University Press. 1989. págs. 149-170

HEIDEGGER, Martin. Marcas do Caminho. Trad. Enio Paulo Giachini e Ernildo Steio. Petrópolis (RJ): Vozes. 2008

MORSON, Gary Saul; EMERSON, Caryl. Mikhail Bakhtin - Criação de uma Prosaĺstica. Trad. Antonio de Padua Danesi. São Paulo: Editora da Universidade de São Paulo, 2008

SHUKMAN, Ann. Bakhtin's Tolstoy Prefaces. In: MORSON, Gary Saul; EMERSON, Caryl (Org.) Rethinking Bakhtin - Extensions and Challenges. Trad. Caryl Emerson. Evanston (IL): Northwerster University Press. 1989. págs. 137-148

TOLSTOI, Leon. Ressurreccion. Trad. e nota preliminar Irene e Laura Andresco. Tomo I. Madrid: Aguilar S.A. 1976, págs. 1597-1885. 